EDITORIAL OPEN

\title{
Npj Quantum Materials as a symbol of international scientific cooperation
}

npj Quantum Materials (2021)6:18; https://doi.

org/10.1038/s41535-021-00322-9

Five years ago, when this journal was first launched, I wrote a note titled "Why do we need another journal"1 outlining my reasons for joining this venture. The overall quality, impact, and significance of the articles that have been published in npj Quantum Materials in the past half-decade amply justify the rationales for the journal that I articulated there.

What I could not have anticipated at the time is the extraordinary commitment and insight of the associate editors who have overseen the refereeing process, and their ability to obtain constructive referee reports from busy people-leaders in the field-and to obtain these in a timely fashion. I have watched the process result in substantive changes to the papers we have ended up publishing and respectful communications with the authors of the papers we ended up declining to publish. It is my impression-from random discussions with colleagues-that this aspect of our editorial process has not gone unnoticed.

In thinking about the coming five years, another aspect of $n p j$ Quantum Materials seems important to me-its deep imbedding in an international intellectual community. There was a time-not so long ago-when it was possible to imagine a near future in which international cooperation would be the norm and in which competition between countries would be no more intense than the competition between rival cross-town football teams (a sport that can be identified in one of two ways-depending on local preference). However, the persistent conflicts of interest between countries has made this millennial dream seem distant. Currently, this is reflected particularly seriously in tensions between the United States and China.

Without down-playing the importance of the issues at stake, it is still possible to celebrate the importance of one area in which the dream is - in large part-a reality. The scientific community-and especially the quantum materials community-is admirably international in its character. Moreover, everyone directly involved recognizes that the exchange of people and ideas, as well as materials and methods, among the various nations of the world has been of inestimable value to everyone.

Npj Quantum Materials reflects this level of world-wide cooperation. It is published by Nature Portfolio with offices in London and Shanghai. It is run (by the indefatigable Jun-Ming Liu) out of Nanjing University in China. The Editors are from China, Germany, Japan and the United States, and the editorial board includes members from these countries as well as Canada, Austria, the Netherlands, Switzerland, and Korea. (It may also be worth noting that the overwhelming majority of the US-based editors are themselves immigrants.) The authors of the papers we have published span the globe more broadly.

I am proud to be a part of this journal, both because of the role it plays in publishing important papers in a vibrant subfield of science, and because of its value as a symbol of international cooperation in science.

Received: 20 January 2021; Accepted: 2 February 2021; Published online: 01 March 2021

Steven Kivelson ${ }^{1 凶}$

'Department of Physics, Stanford University, Stanford, CA, USA.

凶email: kivelson@stanford.edu

\section{REFERENCE}

1. Kivelson, S. Why do we need another journal. npj Quantum Mater. 1, 16006 (2016).

\section{ADDITIONAL INFORMATION}

Supplementary information The online version contains supplementary materia available at https://doi.org/10.1038/s41535-021-00322-9.

Correspondence and requests for materials should be addressed to S.K.

Reprints and permission information is available at http://www.nature.com/reprints

\begin{abstract}
Open Access This article is licensed under a Creative Commons adaptation, distribution and reproduction in any medium or format, as long as you give appropriate credit to the original author(s) and the source, provide a link to the Creative Commons license, and indicate if changes were made. The images or other third party material in this article are included in the article's Creative Commons license, unless indicated otherwise in a credit line to the material. If material is not included in the article's Creative Commons license and your intended use is not permitted by statutory regulation or exceeds the permitted use, you will need to obtain permission directly from the copyright holder. To view a copy of this license, visit http://creativecommons. org/licenses/by/4.0/.
\end{abstract}

(c) The Author(s) 2021 